\title{
Assessing the Effectiveness of Web-Based Tutorials Using Pre- and Post-Test Measurements
}

\author{
Retta Sweat Guy and Millicent Lownes-Jackson \\ Tennessee State University, Nashville, Tennessee, USA
}

\author{
rguy@tnstate.edu mlownes@tnstate.edu
}

\begin{abstract}
Computer technology in general and the Internet in particular have facilitated as well as motivated the development of Web-based tutorials (MacKinnon \& Williams, 2006). The current research study describes a pedagogical approach that exploits the use of self-paced, Web-based tutorials for assisting students with reviewing grammar and mechanics in a business communications course. The adopted tutorial consists of (1) grammatical and mechanical rules, (2) sentence reinforcement exercises, and (3) interactive diagnostic testing, all with immediate feedback and explanations.

The purpose of the study was to determine if the use of Web-based tutorials significantly improved student performance using pre- and post-test measurements. A quasi-experimental design was used to compare learning outcomes. The results indicate that the use of Web-based tutorials to review grammar and mechanics significantly impacted students' scores from pre-test to final post-test.
\end{abstract}

Keywords: Web-based tutorials, interactive tutorials, grammar and mechanics, tutorials, pre- and post-test

\section{Introduction}

The effectiveness of traditional teaching methods has been questioned as educators search for alternative ways of presenting material, engaging students, and improving academic performance (Jain, 2006). As a result of such enquiry, the use of computers and the Internet have become integral parts of student learning in today's classroom (Seal, Przasnyski, and Leon, 2010). Additionally, computers and the Internet have facilitated the development of Web-based tutorials for student learning and assessment across various disciplines (MacKinnon \& Williams, 2006). Bliwise (2005) defines Web-based tutorials as "computerized demonstrations that are used for active learning exercises."

The use of Web-based tutorials has become acceptable as a complement to lectures as it improves

Material published as part of this publication, either on-line or in print, is copyrighted by the Informing Science Institute. Permission to make digital or paper copy of part or all of these works for personal or classroom use is granted without fee provided that the copies are not made or distributed for profit or commercial advantage AND that copies 1) bear this notice in full and 2) give the full citation on the first page. It is permissible to abstract these works so long as credit is given. To copy in all other cases or to republish or to post on a server or to redistribute to lists requires specific permission and payment of a fee. Contact Publisher@InformingScience.org to request redistribution permission. students' level of understanding of materials (T. Mitchell, Chen, \& Macredie, 2005) and allows learners to control the sequence and pace of the instructional materials (Bolliger \& Supanakor, 2011). During the development stages of Webbased tutorials, Dawson (1998) argued that, "while the lectures provide content to make learning possible, tutorials are the major avenue to activate the learning process through preparatory reading and 
subsequent discussion." Other proponents suggest Web-based tutorials:

- provide students with interactive learning environments that appeal to different learning styles;

- allow students to have greater control over their learning;

- afford students the opportunity to learn at their convenience; and

- offer students the opportunity to gain knowledge through the use of audio, visual, and hands-on applications (Birch \& Sankey, 2008; MacKinnon \& Williams, 2006).

On the other hand, opponents argue that drawbacks to using Web-based tutorial include:

- lack of direct feedback;

- lack of discussion;

- lack of evidence to support learning; and

- lack of academic integrity among students (Garfield, 1995; Sweeney, O’Donoghue, \& Whitehead, 2004).

\section{Study Purpose}

Despite considerable research on the outcomes of various teaching approaches at the tertiary level, there have been few investigations assessing student performance using Web-based tutorials. The current study addresses this deficit.

The current research study describes a pedagogical approach that exploits the use of self-paced, Web-based tutorials for assisting students with reviewing grammar and mechanics in a business communications course. The purpose of this study is to determine if the use of Web-based tutorials are beneficial to student learning. Specifically, the research examines the use of Web-based tutorials using pre- and post-test measurements. The following research questions guided this study:

1. Are there significant differences in pre-test and mid-term post-test scores for students using Web-based tutorials?

2. Are there significant differences in pre-test and final post-test scores for students using Web-based tutorials?

3. Are there significant differences in mid-term and final post-test scores for students using Web-based tutorials?

\section{Literature Review}

Experts in the field of performance assessment are actively debating whether students using Webbased tutorials perform equal to or better than students using more traditional methods of instruction. A review of literature reports on a number of primary research studies that have provided comparable data on student performance as well as student perception of Web-based tutorials. Despite the fact that the use of Web-based tutorials has gained momentum in recent years, a discussion examining the relationship between learning styles and instructional methods is warranted.

\section{Relationship between Learning Styles and Web-Based Systems}

Clark (1983) argued that the media (e.g., video, computer, or oral tradition) are merely vehicles that deliver instruction but do not influence student learning. Additionally, Alexander (1995) suggests that we focus on the way in which students learn using the technology rather than the media. 
Parson (1998) stressed the importance of understanding how technology can affect learning when used by different types of learners. Thus, identifying learning styles becomes an important factor in understanding how students perceive and process information in different ways (Ching-Chun \& Gamon, 2002) and how the strategies of learning affect student attitudes toward Web-based systems (Tawei \& Chang, 2011).

According to Keefe (1979), learning styles are generally considered as "characteristic, cognitive, affective, and psychological behaviors that serve as relatively stable indicators of how learners perceive, interact with, and respond to a learning environment"(p.4). Studies have shown a direct correlation exists between student performance and the method of instruction matched to the preferred learning style.

In examining the association between students' learning style and instructional methods, Benham (2002) compared the effectiveness of Web-based and traditional instructor-based training in a computer literacy course using the Kolb learning Style Inventory. The study results suggest that learning styles influenced performance and the study concludes that students who favor instructional methods that include convergers (i.e., thinking and doing) and assimilators (i.e., thinking and watching) were less effective in the Web-based training. Yet, in a similar study, Terrell (2002) found that students with a preference for convergers and assimilators were more effective in the Web-based method of instruction. With similar results, Manochehr (2006) also compared Web-based versus traditional instructor-based training and discovered that students with a preference for convergers and assimilators performed better in the Web-based training while those with a preference for accommodators (i.e., feeling and doing) and divergers (i.e., feeing and watching) performed better in the traditional instructor-based training.

While a number of studies showed that learning style determines preference for Web-based instruction (Aragon, Johnson, \& Shaik, 2002; Terrell, 2002), the majority of research studies show no significant difference in student performance and learning styles relative to Web-based versus traditional instructor-based method of instruction (Brittan-Power, Legum, \& Taylor, 2008; Buerck, Malmstrom, \& Peppers, 2003; McNeal \& Dwyer, 1999). Therefore, Diaz and Cartnal (1999) suggest that if there are no differences in learning styles, then the same learning activities should be effective for both Web-based and traditional instructor-based training and any differences in student performance may be due to other factors.

\section{Student Performance Using Web-Based Tutorials}

Proponents of Web-based tutorials assert that such systems offer opportunities to increase student engagement and understanding of material; thereby, students have the opportunity to complete assignments and receive immediate feedback at any time (Cheng \& Swanson, 2011). The results of various studies conducted across the country indicate the following:

1. Students spend more time studying outside of class and have favorable opinions about using Web-based tutorials (Allain and Williams, 2006; Butler and Zerr, 2005; Lee, Courtney, \& Balassi, 2010; Sagarra \& Zapata, 2008; Smolira, 2008; Zerr, 2007).

2. Students are better prepared for class and are more likely to complete homework and other assignments when Web-based tutorials are used (Lenz, 2010; Zerr, 2007).

3. Students report having a greater understanding of course content when using Web-based tutorials (Lee, et al., 2010; Smolira, 2008).

Early studies have shown that simple and complex material can be learned well in a computerized format such as Web-based tutorials. Worthington, Welsh, Archer, Mindes, and Forsyth (1996) found that students who used computer-based exercises in an introductory psychology class had higher scores on the final exam than students in a lecture-only section of the course. Likewise, M. 
Mitchell and Jolley (1999) found significant positive correlation between students who used a self-guided, Web-based tutorial and exam performance. Additionally, Koch and Gobell (1999) found that Web-based tutorials led to improved accuracy regarding decisions about design issues and the correct choice of statistics in an advanced course on research methods and statistics.

Desrochers, House, and Seth (2001) reported higher scores among students who used Web-based tutorials to apply knowledge of assessment and intervention to a novel clinical situation compared to students who learned the material in a lecture-only format. Similarly, Wilson and Harris (2002) evaluated the use of interactive tutorials in an introductory psychology class and found that students who learned from the Web-based tutorial scored better on exams than students who learned only from classroom lectures.

Varnhagen and Digdon (2002) found that high levels of access and participation in a Web-based interactive learning module were associated with higher exam scores for students learning to understand and critically evaluate published research articles in a research methods course.

Bliwise (2005) conducted a quasi-experimental study in which she compared learning outcomes of students who were enrolled in (1) a class that offered tutorials to students as an extra-credit course option and (2) a lecture-only class. The study consisted of 248 students enrolled in either the control group (no tutorial) or the experimental group (tutorial). The author taught each class maintaining comparable lecture and computer lab structures. Students who completed Web-based tutorials on selected statistical concepts performed better than those who did not use the tutorial on critical items on 4 of the 5 course exams. The findings suggest that Web-based tutorials can be an effective supplement to class lectures for enhancing student learning.

More recently, Tallmadge and Chitester (2010) examined the effectiveness of tutorial use in a physiological chemistry course using pre- and post-test measurements. The pre-test assessed general principles of the topic assumed to be covered in high school. The average score for the pretest was 12 correct responses out of 30 questions $(40 \%)$ with a range of 7 to 23 . The median score for correct responses was 13 . The average score for the post-test improved significantly as compared to the pre-test to 22 out of $30(73 \%)$ with a range of 11 to 27 and a median of 22 . The average score increased $33 \%$, with a minimum increase of $13 \%$ and a maximum increase of $57 \%$ (see table 1). The authors concluded that "using Web-based tutorials assisted students in compensating for insufficient background in chemical principles, allowing the class to progress faster into the biological chemistry" (p. 6).

Table 1: Pre- and Post-Test Correct Responses (as cited in Tallmadge and Chitester, 2010)

\begin{tabular}{|l|l|l|}
\hline & Pre-Test marks out of 30 & Post-Test \\
\hline Average Number of Correct Responses & 12 & 22 \\
\hline Median & 13 & 22 \\
\hline Range & 7 to 23 & 11 to 27 \\
\hline
\end{tabular}

Singh and Haileselassie (2010) developed self-paced interactive problem-solving tutorials for an introductory physics course with the purpose of comparing the performance of students who used the tutorials with those who learned similar content by other means. Students were randomly assigned to one of the following three groups:

- Group 1 consisted of students who used the Web-based tutorials;

- Group 2 consisted of students who used the solutions for the Web-based tutorial problems; and

- Group 3 consisted of students who used the adopted textbook. 
The average performance for groups 1,2 and 3 was $86 \%, 58 \%$, and $11 \%$, respectively. The researchers concluded that the Web-based tutorials significantly impacted student learning.

Don Osborn (2010) compared student learning using a Web-based tutorial versus a print-based tutorial. During a five-year period, a total of 325 students participated in the study and were enrolled in multiple 28 to 35 student sections of an introductory psychology class at a small, historically Catholic liberal arts college in the South. The performance evaluation assessed how well students solve the final exam items. The results showed that students who only had the printbased tutorial available scored lower on the final exam. Overall, students who used the Webbased tutorial became more skillful in analyzing experimental design problems; as a result, the author suggests that the Web-based hypertext tutorial approach is an effective instructional tool when compared to a print-based tutorial.

While the previously mentioned studies found Web-based tutorials to be more effective than classroom lectures and other traditional and non-traditional instructional methods, the following researchers found no significant difference between the use of Web-based tutorials and other instructional formats.

Hurlburt (2001) found that students who learned statistics using a Web-based tutorial performed as well as students in a traditional lecture class on course exams. Likewise, Aberson, Berger, Healy, and Romero (2003) compared test performance of students learning either about the sampling distribution of the mean or hypothesis testing from Web-based interactive tutorials to those exposed to the concepts in a lecture with class demonstrations or standard laboratory sessions. Knowledge significantly increased from pre-tests to post-test; however, improvements were comparable across both learning formats.

Keller, Finkelstein, Perkins, \& Pollock (2006) assessed the effectiveness of a Web-based tutorial in an introductory physics course. The purpose of the study was to determine whether the use of computer-simulated tutorials is as effective as real laboratory equipment. The authors observed no lasting or repeatable significant differences in conceptual understanding between students who used either a computer simulation or real laboratory equipment, suggesting that in the appropriate contexts, simulations can be just as productive as real equipment.

Researchers and instructional designers argue the need to consider both the educational and social aspects of learning rather than solely the technological, and cite the psychosocial environment of classrooms of equal importance with regard to student learning and knowledge creation (Sweeney et al., 2004). Opponents of Web-based tutorials suggest that many colleges and universities have rushed to adopt technology-based methodology without considering ideological, pedagogical, and psychosocial issues (Sweeney \& Ingram, 2001; Thomas, 1999). Opponents also argue that lectures and seminars are economically more feasible and should continue to serve as the main and time-honored means for disseminating knowledge and maintaining interactions between and among faculty and students.

It is against the technology-based classroom culture that the following studies have found lower student performance when using, specifically, Web-based tutorials. For instance, de Jong and van Joolingen (1998) used Web-based tutorials to review conceptual domains and found no general outcome in favor of such tutorials. The inability to deal with expected results and the under-use of features by students who did not successfully use the tutorials were cited as some of the factors that hindered student use of Web-based tutorials. Similarly, Cracolice and Abraham (1996) concluded that, as the difficulty of the problems in a chemistry class increased, students assigned to the printed workbook condition outperformed students assigned to the Web-based tutorial condition. An inference from the research conducted by Elicker, O'Malle, and Williams (2008) showed that the Web-based instructional tools made available to students were ineffective in increasing their performance compared to the easier communication with the instructor. 
Seal, Przasnyski, and Leon (2010) set out to study the impact of Web-based interactive tutorials in order to improve students' learning. The subject pool for the study consisted of 40 College of Business Administration students. Low interactivity tutorials were used to demonstrate modeling concepts, keystrokes, and the mechanics of performing a particular task. Medium interactivity tutorials increased both the range of choices and the frequency of interaction as students were asked to take part in a concept-oriented exercise and were provided feedback about their responses. Specifically, the purpose of this experiment was to see if interactive tutorials improved students' understanding of the spreadsheet modeling of the transportation problem and if increasing levels of interactivity provide a commensurate increase in students' understanding of the modeling process. The researchers found that the low interactivity tutorials significantly improved students' ability to model and solve the transportation problem. However, the medium interactivity tutorials did not show a significant improvement in the students' learning and therefore failed to support the claim that increasing interactivity in Web-based tutorials will help students better learn spreadsheet modeling of the transportation problem.

\section{Student Perception of Web-Based Tutorials}

The literature review revealed both positive and negative responses regarding students' perceptions of Web-based tutorials. Turpen, Finkelstein, and Pollock (2009) present analyses of students' perceptions of Web-based tutorials used in a calculus-based introductory physics course. A survey was used to determine students' perceived utility and enjoyment of tutorials. Students were asked to rank (from 1--no help to 5--very much help) how much the tutorials helped their learning in the course. After a five-year study period, the authors and professors at University of Colorado determined that the students generally did not like the tutorials.

To evaluate the students' perceptions of Web-based tutorial, Jain (2006) developed and administered a questionnaire to 110 students enrolled in her introductory macroeconomic tutorial groups. The survey results indicate that a high percentage of study respondents perceive tutorials to be at least as important as lectures, if not more. A similar study conducted by Bolliger and Supanakorn (2011) revealed that the majority of the study participants thought the tutorials were useful in learning and reviewing the material. The majority of the participants thought the tutorials helped them spend less time in learning the material and completing the assignment.

Retna, Chong, and Cavana (2009) assessed students' perceptions of tutorials and the factors that contribute to their learning in a New Zealand university. Survey questionnaires were administered to management students at the end of their course, to gather information on their perceptions of tutorial effectiveness and to reflect on their overall experiences. Quantitative and qualitative analyses supported the initial hypothesis that the learning environment, positive and constructive feedback, and stimulating tutorials improved student learning and led to higher levels of student satisfaction with their learning experiences. The authors conclude that it is perceived that tutorials help create an environment conducive for learning.

Sweeney et al. (2004) compared students' perspectives on traditional face-to-face tutorials and Web-based tutorials. Their research found that the tutorial approach, despite representing an unknown to students, offered several benefits such as a greater number of participating students, reduced hierarchical divides, reduced race and gender-based inhibitions, and encouragement of collaborative learning. Overall, some students viewed the face-to-face tutorials as relatively easy and the Web-based tutorial as hard work, requiring reflective thinking and a substantial time commitment. Others viewed the Web-based tutorial as enabling a certain freedom of speech and offering a deeper learning approach. 


\section{Methodology}

Business communication classes have a great deal of material to cover. As a result, it's almost impossible to teach grammar, punctuation, and usage skills in addition to teaching business communication writing skills; therefore, it is important to make students responsible for learning or reviewing grammar/punctuation/mechanics - with a minimum of class time devoted to this review. To accomplish this objective, a digitized, interactive, Web-based tutorial was employed as an online study assistant that features self-teaching of grammar and mechanics.

The current study encompasses students from the College of Business at Tennessee State University, a historically Black land-grant institution located in Nashville, Tennessee. Founded in 1912, this comprehensive urban university serves a student population of 9,165 where $74 \%$ are African American, 22\% are Caucasian, and 4\% are reported as other. TSU received accreditation from the Association to Advance Collegiate Schools of Business (AACSB International) a distinguished accrediting institution for business programs in higher education.

\section{Subjects}

Study participants included 198 students who self-enrolled in Business Communications (BISE 3150 ) during a study period of two years beginning fall 2008 through to spring 2010 . The demographics of the sample population included a large percentage of African Americans (74\%), a balance of males $(45 \%)$ and females $(55 \%)$, and a mixture of traditional $(73 \%)$ and nontraditional (27\%) students.

\section{Procedure}

The business communications course is a requisite for all business majors toward graduation with further requirements to maintain at least a grade point average of 2.0 in all core courses. All course sections used in this study were run consecutively and were facilitated by the same professor.

A quasi-experimental design was used to compare learning outcomes of student performance using pre- and post-test measurements of grammar and mechanics. Web-based tutorials, rather than class time, were used to address the prerequisite knowledge. This approach was chosen to minimize the in-class time required to review pre-requisite material.

At the beginning of the course, students were given proficiency test form A as a pretest (see Appendix A). Based on the results of the pre-test, students were required to review grammar and mechanics using Web-based tutorials. The assignment was worth 100 points and was not due until the end of the semester (week 16); however, students were aware that they needed to complete the review prior to mid-term in an attempt to improve grammar and mechanics pre-test scores. To access the Web-based tutorials, students had to either purchase the adopted textbook which included an access code or simply purchase an access code.

A second proficiency test form B, referred to as mid-term post-test (see Appendix B) was administered during mid-term (week 8). If students wanted to take another test to improve their scores, proficiency test form $\mathrm{C}$, referred to as final post-test (see Appendix C) was administered during final exam.

\section{Web-Based Tutorial}

The adopted tutorial enabled students to review an entire business English course-including grammar, punctuation, capitalization, and number style - at their own pace. The "Your Personal Language Trainer" provided hundreds of sentence reinforcement exercises, all with immediate feedback and explanations for the best comprehension and retention. The trainer content included 
the following 11 sections: nouns, pronouns, verbs, adjectives and adverbs, prepositions, commas, semicolons and colons, apostrophes, other punctuation, capitalization, and number usage. An interactive diagnostic test preceded the 11 learning workouts in "Your Personal Language Trainer." This online test included 66 questions that systematically covered all 11 learning workouts. Student performance was assessed based on the following scale:

95 to $100 \% \quad$ You have excellent skills in this category, but you should complete the workouts to be sure you understand and can explain the rules.

85 to $94 \% \quad$ You need a light review. The workouts can help!

75 to $84 \% \quad$ You need to refresh your memory of the rules by completing the workouts.

65 to $74 \% \quad$ You require careful study of the rules in the workouts.

0 to $64 \% \quad Y o u$ need serious study and follow-up reinforcement in the workouts and your textbook. Consider buying and studying a reference manual.

Finally, students were then required to complete the three-step trainer workouts. These workouts provided rules plus exercises to reinforce learning.

Step 1 involved a warm up that reviewed specific grammar rules. Students read the synopsis followed by a quiz.

Step 2 provided special sentences that focused on the target grammar area.

Step 3 provided a quiz that measured how well students improved their language skills.

\section{Findings}

The performance of 198 students, who were self-enrolled in business communication courses, was assessed using pre- and post-test measurements. The data was analyzed using descriptive and inferential statistics for which Statistical Package for Social Sciences (SPSS) was used with the significance level set at $\mathrm{a}=0.05$.

Data analysis in this study consisted of two phases. In Phase 1, frequencies were used to provide summaries about the sample population and the measures.

Within one week of the start of the semester, a pre-test was administered to the students. The pretest examined some of the general principles assumed to be covered in a high school course. The pre-test scores, as presented in Figure 1, shows that the majority of the students (68.3\%) fell below passing with scores 59 and lower, 20\% earned scores ranging from 60-69 and 11.7\% earned scores between 70-79. The low scores indicated that students did need a review of grammar and mechanics. 
Figure 1: Pre-test Grade Averages

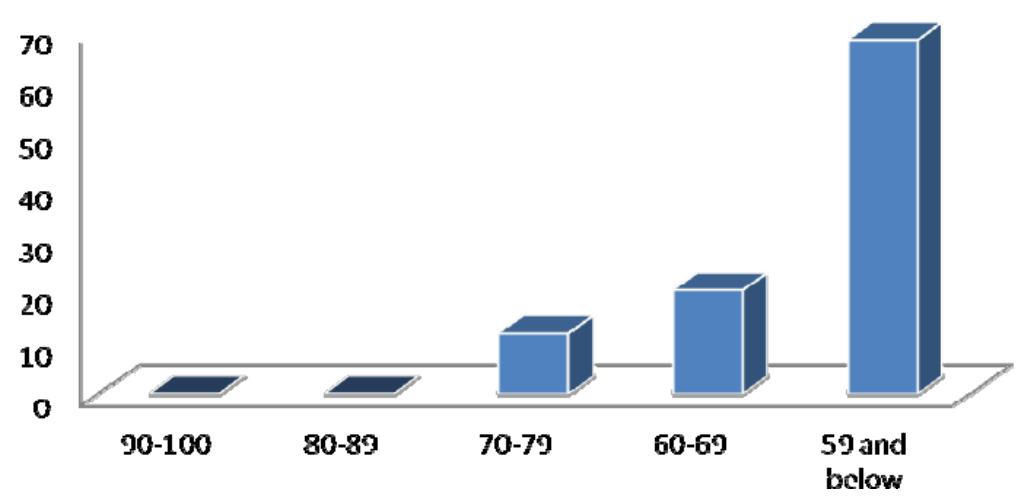

A one-way frequency table was computed to determine the rate of recurrence for each pre-test score, revealing that 18 students earned a score of $58 \%, 17$ students earned 50\%, and 15 students earned $52 \%$ while only 4 students earned a the highest score of $78 \%$ (see Table 2 ).

Table 2: Pre-Test Frequency Count

\begin{tabular}{|c|c|c|c|c|c|}
\hline & & Frequency & Percent & Valid Percent & $\begin{array}{l}\text { Cumulative } \\
\text { Percent }\end{array}$ \\
\hline Valid & 28 & 1 & .5 & .6 & .6 \\
\hline & 32 & 1 & .5 & .6 & 1.1 \\
\hline & 34 & 2 & 1.0 & 1.1 & 2.2 \\
\hline & 36 & 1 & .5 & .6 & 2.8 \\
\hline & 40 & 9 & 4.5 & 5.0 & 7.8 \\
\hline & 42 & 7 & 3.5 & 3.9 & 11.7 \\
\hline & 44 & 8 & 4.0 & 4.4 & 16.1 \\
\hline & 46 & 9 & 4.5 & 5.0 & 21.1 \\
\hline & 48 & 11 & 5.6 & 6.1 & 27.2 \\
\hline & 50 & 17 & 8.6 & 9.4 & 36.7 \\
\hline & 52 & 15 & 7.6 & 8.3 & 45.0 \\
\hline & 54 & 11 & 5.6 & 6.1 & 51.1 \\
\hline & 56 & 13 & 6.6 & 7.2 & 58.3 \\
\hline & 58 & 18 & 9.1 & 10.0 & 68.3 \\
\hline & 60 & 8 & 4.0 & 4.4 & 72.8 \\
\hline & 62 & 10 & 5.1 & 5.6 & 78.3 \\
\hline & 64 & 6 & 3.0 & 3.3 & 81.7 \\
\hline & 66 & 4 & 2.0 & 2.2 & 83.9 \\
\hline & 68 & 8 & 4.0 & 4.4 & 88.3 \\
\hline & 70 & 6 & 3.0 & 3.3 & 91.7 \\
\hline & 72 & 8 & 4.0 & 4.4 & 96.1 \\
\hline & 76 & 3 & 1.5 & 1.7 & 97.8 \\
\hline & 78 & 4 & 2.0 & 2.2 & 100.0 \\
\hline & Total & 180 & 90.9 & 100.0 & \\
\hline Missing & System & 18 & 9.1 & & \\
\hline Total & & 198 & 100.0 & & \\
\hline
\end{tabular}


Similarly to the pre-test, the post-test mid-term scores, as illustrated in Figure 2, reveal that the majority of the students (59.8\%) fell below passing, 27.6\% earned scores ranging from 60-69, $11.5 \%$ earned scores between $70-79$, while only $1.1 \%$ earned scores between $80-89$. The low scores at mid-term represent the low percentage of students who had not completed the Webbased tutorials for grammar and mechanics.

\section{H'igure 2: Post-test Mid-Term Grade Averages}



Frequencies were used to obtain counts for post-test mid-term scores as exhibited in Table 3.

Similarly to the pre-test, 19 students earned 58\%, 15 students earned $62 \%$, and 14 students earned $60 \%$ while only 1 student earned the highest score of $84 \%$.

Table 3: Test Mid-Term Frequency Count

\begin{tabular}{|c|c|c|c|c|c|}
\hline & & Frequency & Percent & Valid Percent & $\begin{array}{l}\text { Cumulative } \\
\text { Percent }\end{array}$ \\
\hline Valid & 24 & 1 & .5 & .6 & .6 \\
\hline & 38 & 1 & .5 & .6 & 1.1 \\
\hline & 40 & 6 & 3.0 & 3.4 & 4.6 \\
\hline & 42 & 5 & 2.5 & 2.9 & 7.5 \\
\hline & 44 & 9 & 4.5 & 5.2 & 12.6 \\
\hline & 46 & 10 & 5.1 & 5.7 & 18.4 \\
\hline & 48 & 9 & 4.5 & 5.2 & 23.6 \\
\hline & 50 & 10 & 5.1 & 5.7 & 29.3 \\
\hline & 52 & 11 & 5.6 & 6.3 & 35.6 \\
\hline & 54 & 13 & 6.6 & 7.5 & 43.1 \\
\hline & 56 & 11 & 5.6 & 6.3 & 49.4 \\
\hline & 58 & 19 & 9.6 & 10.9 & 60.3 \\
\hline & 60 & 14 & 7.1 & 8.0 & 68.4 \\
\hline & 62 & 15 & 7.6 & 8.6 & 77.0 \\
\hline & 64 & 7 & 3.5 & 4.0 & 81.0 \\
\hline & 66 & 5 & 2.5 & 2.9 & 83.9 \\
\hline & 68 & 6 & 3.0 & 3.4 & 87.4 \\
\hline & 70 & 3 & 1.5 & 1.7 & 89.1 \\
\hline & 72 & 7 & 3.5 & 4.0 & 93.1 \\
\hline & 74 & 3 & 1.5 & 1.7 & 94.8 \\
\hline & 76 & 4 & 2.0 & 2.3 & 97.1 \\
\hline
\end{tabular}




\begin{tabular}{|c|c|c|c|c|c|}
\hline & & Frequency & Percent & Valid Percent & $\begin{array}{c}\text { Cumulative } \\
\text { Percent }\end{array}$ \\
\hline & 78 & 3 & 1.5 & 1.7 & 98.9 \\
\hline & 80 & 1 & .5 & .6 & 99.4 \\
\hline & 84 & 1 & .5 & 6 & 100.0 \\
\hline & Total & 174 & 87.9 & 100.0 & \\
\hline Missing & System & 24 & 12.1 & & \\
\hline Total & & 198 & 100.0 & & \\
\hline
\end{tabular}

The post-test final scores as illustrated in Figure 3, shows that more than one-third of the sample population (38.3\%) fell below passing, 36.4\% earned scores ranging from $60-69,21.0 \%$ earned scores between 70-79, while only $3.1 \%$ earned scores between $80-89$ and $1.2 \%$ earned scores between 90-100.

Figure 3: Post-test Final Grade Averages

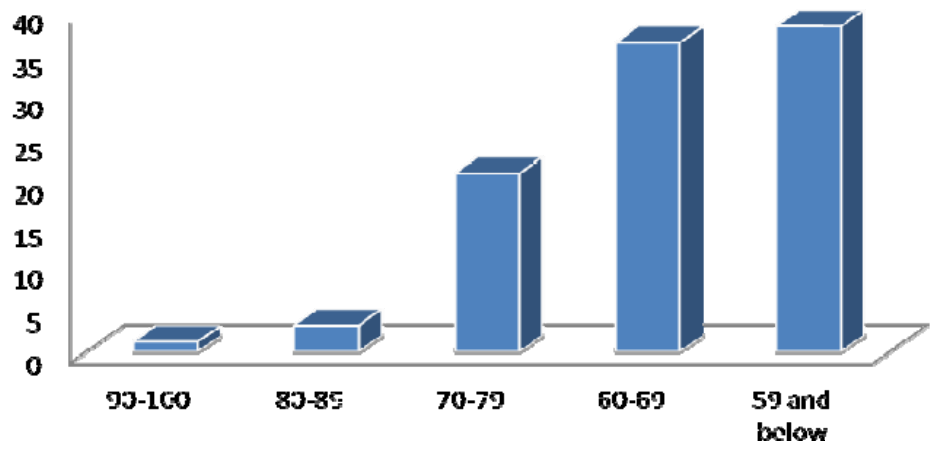

Frequency Table 4 provides the rate of occurrence for post-test final scores exposing a high rate of low marks with 13 students scoring 60\%,62\% and 64\%, uniformly. Quite the reverse was found at the other end of the grading scale revealing 1 student scoring $94 \%, 90 \%$, and $86 \%$, uniformly.

Table 4: Post-Test Final Frequency Count

\begin{tabular}{|c|c|c|c|c|c|}
\hline & & Frequency & Percent & Valid Percent & $\begin{array}{l}\text { Cumulative } \\
\text { Percent }\end{array}$ \\
\hline \multirow[t]{13}{*}{ Valid } & 30 & 1 & .5 & .6 & .6 \\
\hline & 34 & 1 & .5 & .6 & 1.2 \\
\hline & 38 & 1 & .5 & .6 & 1.9 \\
\hline & 40 & 2 & 1.0 & 1.2 & 3.1 \\
\hline & 42 & 2 & 1.0 & 1.2 & 4.3 \\
\hline & 44 & 2 & 1.0 & 1.2 & 5.6 \\
\hline & 46 & 1 & .5 & .6 & 6.2 \\
\hline & 48 & 7 & 3.5 & 4.3 & 10.5 \\
\hline & 50 & 1 & .5 & .6 & 11.1 \\
\hline & 52 & 12 & 6.1 & 7.4 & 18.5 \\
\hline & 54 & 11 & 5.6 & 6.8 & 25.3 \\
\hline & 56 & 9 & 4.5 & 5.6 & 30.9 \\
\hline & 58 & 12 & 6.1 & 7.4 & 38.3 \\
\hline
\end{tabular}




\begin{tabular}{|c|c|c|c|c|c|}
\hline & Frequency & Percent & Valid Percent & $\begin{array}{c}\text { Cumulative } \\
\text { Percent }\end{array}$ \\
\hline & 60 & 13 & 6.6 & 8.0 & 46.3 \\
\hline & 62 & 13 & 6.6 & 8.0 & 54.3 \\
\hline & 64 & 13 & 6.6 & 8.0 & 62.3 \\
\hline & 66 & 12 & 6.1 & 7.4 & 69.8 \\
\hline & 68 & 8 & 4.0 & 4.9 & 74.7 \\
\hline & 70 & 8 & 4.0 & 4.9 & 79.6 \\
\hline & 72 & 11 & 5.6 & 6.8 & 86.4 \\
\hline & 74 & 8 & 4.0 & 4.9 & 91.4 \\
\hline & 76 & 2 & 1.0 & 1.2 & 92.6 \\
\hline & 78 & 5 & 2.5 & 3.1 & 95.7 \\
\hline & 80 & 1 & .5 & .6 & 96.3 \\
\hline & 82 & 1 & .5 & .6 & 96.9 \\
\hline & 84 & 2 & 1.0 & 1.2 & 98.1 \\
\hline & 86 & 1 & .5 & .6 & 98.8 \\
\hline & 90 & 1 & .5 & .6 & 99.4 \\
\hline & 94 & 1 & .5 & .6 & 100.0 \\
\hline & Total & 162 & 81.8 & 100.0 & \\
\hline Missing & System & 36 & 18.2 & & \\
\hline Total & & 198 & 100.0 & & \\
\hline
\end{tabular}

Table 5 displays measures of central tendency and dispersion used to describe and compare scores of the pre-test, mid-term post-test, and final post-test. From these measures, it is evident that the final post-test scores were slightly higher than both the pre-test and mid-term post-test.

Table 5 Pre-Test, Mid-Term and Final Post-Test Statistics

\begin{tabular}{|l|l|r|r|r|}
\hline \multicolumn{2}{|c|}{} & Pre-Test & $\begin{array}{c}\text { Mid-Term } \\
\text { Post-Test }\end{array}$ & $\begin{array}{c}\text { Final Post- } \\
\text { Test }\end{array}$ \\
\hline \multirow{2}{*}{ Mean } & Valid & 180 & 174 & 162 \\
\cline { 2 - 5 } & Missing & 18 & 24 & 36 \\
\hline Median & 55.20 & 56.82 & 62.00 \\
\hline Mode & 54.00 & 58.00 & 62.00 \\
\hline Std. Deviation & 58 & 58 & $60(\mathrm{a})$ \\
\hline Minimum & 10.247 & 10.093 & 10.599 \\
\hline Maximum & 28 & 24 & 30 \\
\hline
\end{tabular}

(a) Multiple modes exist. The smallest value is shown.

In the second phase of the data analysis, a series of pair-sample t-test were run to compare the average performance between the pre- and post-test measurements.

The first paired-sample analysis was run to determine whether the mean score for the pretest differs significantly from the mean score for the mid-term post-test. As revealed in Tables 6 and 6.1, the results indicate that the mean score on the mid-term post-test $(M=56.76)$ was slightly higher than the mean score on the pre-test (55.46). Additionally, the results indicate that a significant positive correlation exists between the pre-test and the mid-term post-test $(\mathrm{r}=.656, \mathrm{p}<.05)$, suggesting that students who score high on one of the exams tend to score high on the other. Likewise, students who score low on one exam also tend to score low on the other. 
Table 6: Pre-Test and Mid-Term Post-Test Paired Samples Statistics

\begin{tabular}{|l|r|r|r|r|}
\hline & Mean & \multicolumn{1}{|c|}{$\mathrm{N}$} & Std. Deviation & $\begin{array}{c}\text { Std. Error } \\
\text { Mean }\end{array}$ \\
\hline Pre-Test & 55.46 & 156 & 10.659 & .853 \\
\hline $\begin{array}{l}\text { Mid-Term Post- } \\
\text { Test }\end{array}$ & 56.76 & 156 & 9.804 & .785 \\
\hline
\end{tabular}

Table 6.1: Pre-Test and Mid-Term Post-Test Paired Samples Correlations

\begin{tabular}{|l|r|r|r|}
\hline & \multicolumn{1}{|c|}{ N } & Correlation & Sig. \\
\hline $\begin{array}{l}\text { Pretest and Mid-Term } \\
\text { Post- }\end{array}$ & 156 & .656 & .000 \\
\hline
\end{tabular}

The second paired-sample analysis was run to determine whether the mean score for the pretest differs significantly from the mean score for the final post-test. As revealed in Tables 7 and 7.1, the results indicate that the mean score on the final post-test $(\mathrm{M}=61.93)$ was significantly higher than the mean score on the pre-test (54.74). Additionally, the results indicate that a significant positive correlation exists between the pre-test and the final post-test $(r=.543, p<.05)$, suggesting that students who score high on one of the exams tend to score high on the other. Likewise, students who score low on one exam also tend to score low on the other.

Table 7: Pre-Test and Final Post-Test Paired Samples Statistics

\begin{tabular}{|l|r|r|r|r|}
\hline & Mean & N & Std. Deviation & $\begin{array}{c}\text { Std. Error } \\
\text { Mean }\end{array}$ \\
\hline Pre-Test & 54.74 & 144 & 10.508 & .876 \\
\hline Final Post-Test & 61.93 & 144 & 10.325 & .860 \\
\hline
\end{tabular}

Table 7.1: Pre-Test and Final Post-Test Paired Samples Correlations

\begin{tabular}{|l|r|r|c|}
\hline & N & Correlation & Sig. \\
\hline $\begin{array}{l}\text { Pre-Test and Final Post- } \\
\text { Test }\end{array}$ & 144 & .543 & .000 \\
\hline
\end{tabular}

Finally, the third paired-sample analysis was run to determine whether the mean score for the mid-term post-test differs significantly from the mean score for the final post-test. As revealed in Tables 8 and 8.1, the results indicate that the mean score on the final post-test $(M=62.20)$ was slightly higher than the mean score on the mid-term post-test (56.20). Additionally, the results indicate that a significant positive correlation exists between the mid-term post-test and the final post-test $(\mathrm{r}=.674, \mathrm{p}<.05)$, suggesting that students who score high on one of the exams tend to score high on the other. Likewise, students who score low on one exam also tend to score low on the other.

Table 8: Mid-Term and Final Post-Tests Paired Samples Statistics

\begin{tabular}{|l|r|r|r|r|}
\hline & Mean & N & Std. Deviation & $\begin{array}{c}\text { Std. Error } \\
\text { Mean }\end{array}$ \\
\hline $\begin{array}{l}\text { Mid-Term Post- } \\
\text { Test }\end{array}$ & 56.53 & 160 & 10.065 & .796 \\
\hline Final Post-Test & 62.20 & 160 & 10.474 & .828 \\
\hline
\end{tabular}

Table 8.1 Mid-Term and Final Post-Tests Paired Samples Correlations

\begin{tabular}{|l|r|r|r|}
\hline & N & Correlation & Sig. \\
\hline $\begin{array}{l}\text { Mid-Term and Final Post- } \\
\text { Test }\end{array}$ & 160 & .674 & .000 \\
\hline
\end{tabular}




\section{Study Limitations}

As with any research, there are a number of limitations that may impact this study; accordingly, caution is necessary when interpreting the findings.

While this study provides research on a population that is underrepresented in the literature, it also gives way to the first limitation in focusing solely on participants attending a minorityserving institution with no comparative data from a majority-serving institution. The second limitation pertains to missing data that was excluded from the analysis. The differences in the frequency count for exam completions of the pre-test and post-tests scores were due to students enrolling in the course after the pre-test was administered and students withdrawing from the course after mid-term and before the final exam. Missing data can be problematic because the means of the larger study participants is estimated with less error than the means of the smaller study participants. Thus, the missing data in this study is classified as "missing at random" because of the probability that missing pretest scores is unrelated to the value of other tests scores.

The course used for this study was business related which addresses the third limitation that frames the assumption not all disciplines have courses that are compatible with the use of Webbased tutorials.

\section{Conclusion}

Computer technology in general and the Internet in particular have facilitated as well as motivated the development of Web-based tutorials (MacKinnon \& Williams, 2006). As a computerbased learning resource, Web-based tutorials support active learning environments and are designed to complement class lectures.

From the prevailing research, we can conclude that the use of Web-based tutorials as a means to (a) review prerequisite material, (b) foster knowledge and skill acquisition, (c) transfer knowledge to new situations, and (d) support a variety of problem-solving techniques enhances both student performance and the quality of the course (Bliwise, 2005; Osborn, 2010; Singh \& Haileselassie, 2010; Tallmadge \& Chitester, 2010).

The current study may serve to further affirm the findings of Tallmadge and Chitester (2010) who propose that Web-based tutorials assist students in compensating for insufficient background in any subject. Additionally, the results of the current study are consistent with others (Tallmadge and Chitester, 2010; Singh and Haileselassie, 2010; and Osborn, 2010) suggesting that Webbased tutorials are highly effective for student learning. Specifically, the use of Web-based tutorials to review grammar and mechanics significantly impacted students' scores from pre-test to final post-test.

Although Web-based training is becoming a phenomenon in education today because of its flexibility and convenience, it is vitally important to address those issues that adversely impact retention and success in this environment. Therefore, future research should more aggressively investigate instructional design and learning styles relative to Web-based environments.

\section{References}

Aberson, C., Berger, D., Healy, M., \& Romero, V. (2003). Evaluation of an interactive tutorial for teaching hypothesis testing concepts. Teaching of Psychology, 30, 75-78.

Alexander, S. (1995). Teaching and learning on the World Wide Web. AusWeb95: The First Australian WorldWideWeb Conference. Available: http://ausweb.scu.edu.au/aw95/education2/alexander/

Allain, R., \& Williams, T. (2006). The effectiveness of online homework in an introductory science class. Journal of College Science Teaching, 35(6), 28-30. 
Aragon, S., Johnson, S., \& Shaik, N. (2002). The influence of learning style preferences on student success in online versus face-to-face environments. American Journal of Distance Education, 16(4), 227-244.

Benham, C. (2002) Training effectiveness, on-line delivery, and the influence of learning style. Proceedings of the 2002 ACM Special Interest Group on Computer Personnel Research Conference, 41-46. Kristiansand, Norway.

Birch, D., \& Sankey, M. (2008). Drivers for and obstacles to the development of interactive multimodal technology-mediated distance higher education courses. International Journal of Education and Development Using ICT, 4(1), 66-79.

Bliwise, N. (2005). Web-based tutorials for teaching introductory statistics. Journal of Educational Computing Research, 33(3), 309-325.

Bolliger, D., \& Supanakorn, S. (2011). Learning styles and student perceptions of the use of interactive online tutorials. British Journal of Educational Technology, 42(3), 470-481.

Brittan-Powell, C., Legum, H., \& Taylor, E. (2008). The relationship between student learning style, selection of course delivery format, and academic performance. International Journal of Instructional Technology and Distance Learning, 5(5), 41-46.

Buerck, J., Malmstrom, T. \& Peppers, E. (2003). Learning environments and learning styles: Nontraditional student enrollment and success in an Internet-based versus a lecture-based computer science course. Learning Environments Research, 6(2), 137-155.

Butler, M., \& Zerr, R. (2005). The use of online homework systems to enhance out-of-class student engagement. International Journal for Technology in Mathematics Education, 12(2), 51-58.

Cheng, J., \& Swanson, Z. (2011). An examination of the effects of Web-based tutorials on accounting student learning outcomes. Review of Higher Education and Self-Learning, 4(10), 14-28.

Ching-Chun, S., \& Gamon, J. (2002). Relationships among learning strategies, patterns, styles, and achievement in Web-based courses. Journal of Agricultural Education, 43(4), 1-11.

Clark, R. (1983). Reconsidering research on learning from media. Review of Educational Research, 53(4), 445-459.

Cracolice, M., \& Abraham, M. (1996). A comparison of computer-assisted instruction, semi-programmed instruction, and teaching assistant-led instruction in general chemistry. School Science and Mathematics, 96, 215-221.

Dawson, S. (1998). Effective tutorial teaching. Melbourne: RMIT Publishing.

de Jong, T., \& van Joolingen, W. (1998). Scientific discovery learning with computer simulations of conceptual domains. Review of Educational Research, 68(2), 179-201.

Desrochers, M., House, A., \& Seth, P. (2001). Supplementing lecture with simulations in developmental disabilities: SIDD software. Teaching of Psychology, 28, 227-230.

Diaz, D., \& Cartnal, R. (1999). Students' learning styles in two classes: Online distance learning and equivalent on-campus. College Teaching, 47(4), 130-135.

Elicker, J., O'Malle, A., \& Williams, C. (2008). Does an interactive Web-CT site help students learn? Teaching of Psychology, 35, 126-131.

Garfield, J. (1995). How students learn statistics. International Statistics Review, 63, 25-34.

Hurlburt, R. (2001). 'Lectlets' deliver content at a distance: Introductory statistics as a case study. Teaching of Psychology, 28, 15-20.

Jain, A. (2006). Students' perceptions of workshop based introductory macro-economic tutorials: A survey. Economic Papers, 25(3), 235-251.

Keefe, J. (1979). Learning style: An overview. In J. W. Keefe (Ed.), Learner learning styles: Diagnosing and prescribing programs. Reston: NASSP. 
Keller, C., Finkelstein, N., Perkins, K., \& Pollock, S. (2006). Assessing the effectiveness of a computer simulation in conjunction with tutorials in introductory physics in undergraduate physics recitations. American Institute of Physics, 109-112.

Koch, C., \& Gobell, J. (1999). A hypertext based tutorial with links to the Web for teaching statistics and research methods. Behavior Research methods, Instruments \& Computers, 31, 7-13.

Lee, W., Courtney, R., \& Balassi, S. (2010). Do online homework tools improve student results in principles of microeconomics courses? The American Economic Review, 100(2), 286-287.

Lenz, L. (2010). The effect of a Web-based homework system on student outcomes in a first-year mathematics course. Journal of Computers in Mathematics and Science Teaching, 293, 233-246.

MacKinnon, G., \& Williams, P. (2006). Models for integrating technology in higher education: The physics of sound. Journal of College Science Teaching, 35(7), 22-25.

Manochehr, N. (2006). The influence of learning styles on learners in elearning style environments: An empirical study. Computers in Higher Education Economics Review, 18, 10-14.

McNeal, H., \& Dwyer, D. (1999). Effect of learning style on consistent and inconsistently designed instruction. International Journal of Instructional Media, 26(3), 337-345.

Mitchell, M., \& Jolley, J. (1999). The correlation: A self-guided tutorial. Teaching of Psychology, 26, 298299.

Mitchell, T., Chen, S., \& Macredie, R. (2005). The relationship between Web enjoyment and student perceptions and learning using Web-based tutorial. Learning, Media and Technology, 30(1), 27-40.

Osborn, D. (2010). Do print, Web-based or Blackboard integrated tutorial strategies differentially influence student learning in an introductory psychology class? Journal of Instructional Psychology, 37(3), 247251.

Parson, R. (1998). An investigation into instruction available on the World Wide Web. Available at http://www.osie.on.ca/ rparson/out1d.htm

Retna, K., Chong, E., \& Cavana, R. (2009). Tutors and tutorials: Students' perceptions in a New Zealand university. Journal of Higher Education Policy and Management, 31(3), 251-260.

Sagarra, N., \& Zapata, G. (2008). Blending classroom instruction with online homework: A study of student perceptions of computer-assisted L2 learning. ReCall, 20(2), 208-224.

Seal, K., Przasnyski, Z., \& Leon, L. (2010). How levels of interactivity in tutorials affect students' learning of modeling transportation problems in a spreadsheet. Decision Sciences Journal of Innovative Education, 8(1), 75-94.

Singh, C., \& Haileselassie, D. (2010). Developing problem-solving skills of students taking introductory physics via Web-based tutorials. Journal of College Science Teaching, 42-49.

Smolira, J. (2008). Student perceptions of online homework in introductory finance courses. Journal of Education for Business, 84(2), 90-95.

Sweeney, J., \& Ingram, D. (2001). A comparison of traditional and Web-based tutorials in marketing education. Journal of Marketing Education, 23(1), 55-62.

Sweeney, J., O'Donoghue, T., \& Whitehead, C. (2004). Traditional face-to-face and Web-based tutorials: A study of university students' perspectives on the roles of tutorial participants. Teaching in Higher Education, 9(3), 311-323.

Tallmadge, W., \& Chitester, B. (2010). Integrating concepts using online tutorials in a freshman chemistry course. Transformative Dialogues: Teaching and Learning Journal, 4(2), 1-7.

Tawei, D., \& Chang, C. (2011). The effects of academic discipline and gender difference on Taiwanese college students' learning styles and strategies in Web-based learning environments. The Turkish Online Journal of Educational Technology, 10(3), 265-272. 
Terrell, S. (2002). Learning style as a predictor of success in a limited residency doctoral program. The Internet in Higher Education, 5(4), 345-352.

Thomas, M. (1999). Impacting on communication and learning: When communication technologies constrain communication. Paper presented at Australian Association for Research in Education, Melbourne.

Turpen, C., Finkelstein, N., \& Pollock, S. (2009). Towards understanding classroom culture: Students' perceptions of tutorials. Proceedings of Physics Education Research Conference, American Institute of Physics, 285-288.

Varnhagen, C., \& Digdon, N. (2002). Helping students read reports of empirical research. Teaching of Psychology, 29, 160-164.

Wilson, S., \& Harris, A. (2002). Evaluation of The Psychology Place: A Web-based instructional tool for psychology courses. Teaching of Psychology, 29, 165-168.

Worthington, E., Welsh, J., Archer, C., Mindes, E., \& Forsyth, D. (1996). Computer assisted instruction as a supplement to lectures in an introductory psychology class. Teaching of Psychology, 23, 175-181.

Zerr, R. (2007). A quantitative and qualitative analysis of the effectiveness of online homework in firstsemester calculus. Journal of Computers in Mathematics and Science Teaching, 26(1), 55-73. 


\section{Proficiency Test -- Appendix A}

Grammar: In the space provided, write the letter indicating the word that correctly completes each sentence. Use only one answer for each question.

1. If I (a) was (b) were you, I would take the job.

2. She dropped off her report when she (a) come (b) came over last week.

3. A list showing all the documents prepared for the attorneys (a) was (b) were missing.

4. An executive's time and energy (a) has (b) have to remain focused on achieving corporate goals.

5. How important (a) is (b) are salary, benefits, and job security to you?

6. Please order supplies for (a) her and me (b) her and I (c) she and I.

7. All the new equipment (a) seem (b) seems to be working satisfactorily.

8. (a) Anyone (b) Any one of the computers may need to be replaced shortly.

9. I would appreciate (a) you (b) your (c) you're sending the application immediately.

10. The group of players, coaches, and fans (a) is (b) are booking a charter flight.

11. Sixty days (a) is (b) are the period of the loan.

12. Special reports must be written by (a) whoever (b) whomever has a sales problem.

13. One of the men left (a) his (b) their tennis shoes in the locker room.

14. The boss told Maria not to take the criticism (a) personal (b) personally.

15. Every employee may have (a) their (b) his or her (c) his (d) her tuition reimbursed.

Mechanics: For each of the following sentences, select one letter to identify faults in

(a) Commas or semicolons

(b) Punctuation other than commas or semicolons (including hyphens and apostrophes)

(c) Symbols (including dollar and percent signs)

(d) Number expression (word or figure form)

(e) Capitalization

16. The newly-passed legislation will affect taxes in Texas, California, and Michigan.

17. Erics report, which was entitled "Living in a Digital World," caused a stir.

18. Stockholders for IBM could attend the meeting or they could return their proxies.

19. We are earning 42 dollars on every item; however, total sales are slow.

20. The President of DataTech met with the Vice President to discuss the 9 percent dip in sales.

21. If we receive all the figures we will sign the contract July 1 in our headquarters.

22. The memo from our Human Resources Department is quite clear don't you think?

23. All three collectors, by the way, specialized in antique german and dutch coins.

24. When Alicia is absent, we have only 3 operators in our Customer Service Department.

25. We ordered 15 Pentax Cameras to be awarded as prizes.

26. Our interviewing team consists of these people: Ann Simms, Accounting, Tom Burns, Human Resources, and Carlos Santana, Operations.

27. My graduating class is having it's ten-year reunion June 10.

28. The stockholders' meeting was heavily advertised, however, attendance was light.

29. To improve their english, many Japanese students purchased the book entitled The Power of Language is Yours.

30. Would you please send two copies of Invoice No. 39-5001? 
Form A

Page 2

Confusing Words: In the space provided, write the letter of the word that best completes each sentence.

31. Her (a) principal (b) principle concern was investment safety.

32. The recent decline in prices will surely (a) effect (b) affect the entire market.

33. Fidelity's brochure (a) assured (b) insured (c) ensured prospective investors that their money would be in good hands.

34. Every new investor was given (a) complementary (b) complimentary concert tickets.

35. Good researchers (a) sight (b) site (c) cite the sources of all references.

36. After the theft everyone became more (a) conscience (b) conscious of equipment security.

Spelling: For each line of words, indicate the letter of any misspelled word. If no word is misspelled, write (e). For each numbered item provide only one answer.

(a)

37. accommodate

38. neccessary

39. efficient

40. argument

41. miscelaneous

42. budget

43. congratulate

44. similar

45. consistent (b)

existence
practical
independent
convenient
occurred
accross
committee
priviledge
incidentally

(c)

excellent
sincerely
seperate
government
receive
consecutive
analyse
offered
equipped

(d)

feasable

volume

usable

definitly

sufficient

immediate

restaurant

license

becomming

Sentence Structure: In the space provided, identify any sentence fault by selecting one of the following letters. If the sentence is correct, select (d).
(a) Faulty pronoun reference
(b) Sentence fragment
(c) Comma splice (comma joining clauses inappropriately)
(d) Sentence is correct.

46. We've added fax machines and modems, consequently we must install two new telephone lines.

47. Our office recycles paper and conserves energy because it helps save the environment.

48. A number of stockholders who attended the meeting and expected to voice their opinions.

49. Membership in the organization is voluntary; contributions and grants are the only means of support. This makes it difficult to continue a high level of support.

50. Sales are increasing slowly, profits will respond soon. 


\section{Proficiency Test -- Appendix B}

Grammar: In the space provided, write the letter indicating the word that correctly completes each sentence. Use only one answer for each question.

1. Kevin found it difficult to (a) chose (b) choose a color for his new truck.

2. If Laura had (a) saw (b) seen the report, she might have caught the error.

3. The company's full range of products and services (a) is (b) are offered locally.

4. Only the production cost and the markup of each item (a) was (b) were known.

5. Lying on the table (a) is (b) are the newspaper, two magazines, and airline tickets.

6. Send updated contracts to (a) he and I (b) him and I (c) him and me (d) he and me.

7. Most of the new equipment (a) appear (b) appears to be working well.

8. (a) Everyone (b) Every one of the applicants presented a laser-printed résumé.

9. Bill would appreciate (a) you (b) your answering his telephone when he is away.

10. A record of all dividends, rents, royalties, and pensions (a) was (b) were requested.

11. Before you may rent a tandem bicycle, $\$ 50$ (a) is (b) are required as a deposit.

12. Dr. Lee will see (a) whoever (b) whomever is next in line.

13. The committee submitted (a) it's (b) its (c) their report yesterday.

14. To reduce costs, management pushed for a settlement (a) quick (b) quickly.

15. Every new employee should receive (a) his (b) her (c) his or her (d) their orientation packet.

Mechanics: For each of the following sentences, select one letter to identify faults in

(a) Commas or semicolons

(b) Punctuation other than commas or semicolons (including hyphens and apostrophes)

(c) Symbols (including dollar and percent signs)

(d) Number expression (word or figure form)

(e) Capitalization

16. Our newly-hired supervisor was scheduled to see representatives from HewlettPackard, Xerox, and Canon.

17. Jennifers presentation, which was entitled "How to Make Computer Graphics," was excellent.

18. Employees at the Minneapolis-based plant could earn 5 percent interest or they could withdraw their funds for deposit elsewhere.

19. Each office chair lists for 98 dollars; however, we expect to pay less.

20. The Vice President and Marketing Director were called to the President's office.

21. If both sides are in agreement the contract will be signed Monday, April 2.

22. The positions in our Marketing Department were advertised last week weren't they?

23. All nine investors, nevertheless, purchased European and latin American stocks.

24. If I remember correctly, I sent only 4 e-mail messages in the morning.

25. Our two-year-old Canon Copier is still running well.

26. The committee selected three potential convention cities; Atlanta, Georgia; San Antonio, Texas; and Anaheim, California.

27. TechTronics will move it's headquarters to Purchase, New York, within eight months.

28. All customers' addresses must be accurate, therefore, we must check the list again.

29. Because they spoke little spanish, many visitors purchased the book entitled Speak Like a Native in Just Ten Days.

30. Would you please send two copies of IRS Form No. 1099? 
Form B

Page 2

Confusing Words: In the space provided, write the letter of the word that best completes each sentence.

31. Although it was only a (a) miner (b) minor event, management took notice.

32. His (a) principle (b) principal problem was written communication.

33. New taxation laws will (a) effect (b) affect all corporations.

34. Each property owner must sign a (a) waiver (b) waver before construction can begin.

35. Because security takes (a) precedence (b) precedents over all other factors, we're seeking safe investments.

36. Each new customer was given 1,000 (a) complementary (b) complimentary checks.

Spelling: For each line of words, indicate the letter of any misspelled word. If no word is misspelled, write (e). For each numbered item provide only one answer.

(a)

37. absence

38. embarrass

39. knowledgeable

40. recommendation

41. column

42. imediate

43. prevalent

44. business

45. February (b)

calender

dissatisfied

ommission

receive

consecutive

referred

noticeable

acommodate

usually (c)

convenient

irrelavant

prominent

volumn

familar

separate

ninth

height

unecessarily (d)

interrupt immediate questionnaire writing definitely omitted undoubtedly guarantee surprise

Sentence Structure: In the space provided, identify any sentence fault by selecting one of the following letters. If the sentence is correct, select (d).
(a) Faulty pronoun reference
(b) Sentence fragment
(c) Comma splice (comma joining clauses inappropriately)
(d) Sentence is correct.

46. Our deadline is June 1, however we may receive an extension.

47. Our specialists are trained in retirement planning, investment strategies, and working capital management. This explains our strength.

48. Any number of investors who are looking for flexible leasing arrangements for new equipment.

49. Rick suggested flexible work schedules for all who requested them and an extensive revamping of medical benefits. That was a big hit with all employees.

50. The bond market is advancing slowly, the stock market is moving forward rapidly. 
Proficiency Test -- Appendix C

Grammar: In the space provided, write the letter indicating the word that correctly completes each sentence. Use only one answer for each question.

1. If you (a) was (b) were in my position, I'm sure you would do the same thing.

2. Computer chips were (a) stolen (b) stole last weekend from two warehouses.

3. Here (a) is (b) are the complete list of names and addresses.

4. Considerable time and money (a) was (b) were spent on publicity for the event.

5. The president told Jeffrey and (a) I (b) me (c) myself that we would start Monday.

6. Each of the classifications (a) contain (b) contains four parts.

7. (a) Any one (b) Anyone of our 200 employees is eligible to win the prize trip to Hawaii.

8. Although some checks were delayed, (a) yours (b) your's was delivered on time.

9. One hundred dollars (a) is (b) are too much to pay for one parking ticket!

10. A long line of applicants (a) is (b) are waiting to apply for the advertised jobs.

11. The first new computer goes to (a) whoever (b) whomever is at the top of the list.

12. I certainly appreciate (a) you (b) your responding to my e-mail messages so promptly.

13. Someone on the women's team left (a) her (b) their purse in the locker room.

14. All student learners were instructed to drive (a) careful (b) carefully near the school.

15. Every graduate may pick up (a) their (b) his or her (c) his (d) her diploma today.

Mechanics: For each of the following sentences, select one letter to identify faults in

(a) Commas or semicolons

(b) Punctuation other than commas or semicolons (including hyphens and apostrophes)

(c) Symbols (including dollar and percent signs)

(d) Number expression (word or figure form)

(e) Capitalization

16. The highly-regarded engineer was hired to work on water projects in Utah, Colorado, and California.

17. Erika may compile the list of names and addresses of customers or Steven may do it.

18. Tim Roths screenplay, which was entitled "Tattooed Teenage Aliens," made the rounds of Hollywood producers.

19. We were offered fifty-three dollars a share; however, we are not ready to sell.

20. If you return the entry form by June 15 you will be eligible to win $\$ 50,000$.

21. Both our President and Sales Manager were unhappy with the 2 percent sales dip.

22. If the manager agrees, we will try to hire 2 temporary employees.

23. Regulators feel, nevertheless, that the japanese yen and the european euro will remain strong in the currency market.

24. Will you please send me a copy of Invoice No. 20-4991?

25. All customers' addresses were checked, however, some still have incorrect zip codes.

26. The need for Spanish-speaking teachers is discussed in the Board of Education's booklet entitled "Closing the gap: Language Skills across the Curriculum."

27. President Bush returned from Europe, and immediately addressed Congress.

28. On May 5 th my boat and its trailer will be repainted.

29. When we went fishing we caught a 20-pound Atlantic salmon at the privately owned lake.

30. We brought some Ziploc Bags; however, we did not have enough to package all the items. 
Form C

Page 2

Confusing Words: In the space provided, write the letter of the word that best completes each sentence.

31. Our realtor promised to (a) apprise (b) appraise each prospective buyer of the unusual contract terms.

32. Homeowners are (a) liable (b) libel for "attractive nuisances" on their property.

33. If you (a) altar (b) alter any wording in the contract, you must initial the changes.

34. Stacy had to consult her (a) conscious (b) conscience before resigning her position.

35. Restaurant patrons receive a (a) complimentary (b) complementary glass of wine with their meals on Wednesday evenings.

36. Dr. Myers considered himself a person of high (a) principals (b) principles.

Spelling: For each line of words indicate the letter of any misspelled word. If no word is misspelled, write (e). For each numbered item provide only one answer.

(a)

37. seperate

38. accommodate

39. column

40. apointment

41. occurred

42. automatically

43. criticize

44. courteous

45. libary (b)

miscellaneous
consistent
convenint
committee
opportunity
Febuary
definitely
efficient
emphasize

(c)

$\begin{array}{ll}\text { truly } & \text { valuable } \\ \text { milage } & \text { occasionally } \\ \text { mortgage } & \text { necessary } \\ \text { immediate } & \text { irrelevant } \\ \text { pamphlet } & \text { permenant } \\ \text { fourth } & \text { genuine } \\ \text { desirable } & \text { serprise } \\ \text { goverment } & \text { prominent } \\ \text { ninety } & \text { therefore }\end{array}$

Sentence Structure: In the space provided, identify any sentence fault by selecting one of the following letters. If the sentence is correct, select (d).
(a) Faulty pronoun reference
(b) Sentence fragment
(c) Comma splice (comma joining clauses inappropriately)
(d) Sentence is correct .

46. Employers usually have stacks of résumés from talented applicants, therefore your résumé must be flawless.

47. A vehicle apparently ran off Kelton Road and struck the mail box as it attempted to get back on the roadway.

48. Although few applicants among the most recent candidates had the proper qualifications for the opening in our Customer Service Department.

49. Many students are completing internships, then they are more employable.

50. Antiwar protesters released live cockroaches inside the White House on Friday, and they were arrested when they left and blocked a security gate. 


\section{Biographies}

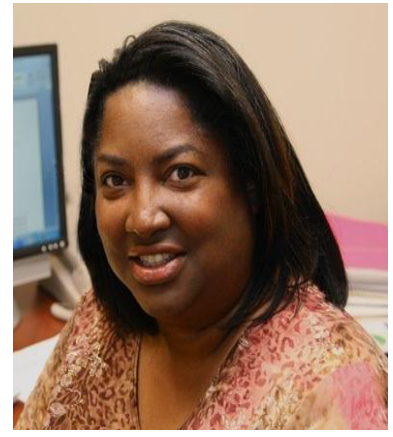

Dr. Retta Guy has an Ed.D. in Curriculum and Instruction with emphasis in Instructional Systems Design from the University of Kentucky. Currently, she is an Associate Professor in the Department of Business Information Systems at Tennessee State University in Nashville. As an active author, Dr. Guy's scholarly publications include an authored book entitled "The Digitally Disinterested," two edited books entitled "The Evolution of Mobile Teaching and Learning" and "Mobile Learning: Pilot Projects and Initiatives," 6 book chapters, $25+$ articles, and 10 refereed proceedings to date. Dr. Guy's intellectual interests include the use of digital technologies to augment teaching and learning, instructional design and assessment, as well as distance learning with specific emphasis in hybrid, online and mobile teaching and learning.

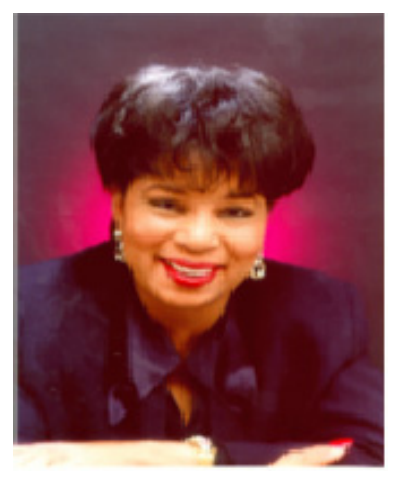

Dr. Millicent Lownes-Jackson is the Interim Provost and Executive Vice President for Academic Affairs at Tennessee State University. She is a small business specialist, author of 15 books, an entrepreneur, newspaper columnist, researcher, certified small business coach, and a tenured Professor of Management. Dr. Lownes-Jackson's educational background includes a Bachelor of Business Administration Degree from Fisk University. She also has a Master of Business Administration Degree and a Doctor of Philosophy Degree, both of which were conferred by Vanderbilt University. Dr. Lownes-Jackson has many research articles, publications and talk show appearances to her credit. She has been featured in numerous stories including articles appearing in Black Enterprise magazine, Contempora magazine, the Tennessee Tribune and the Urban Journal. 